This article is available open access under a CC BY-ND 4.0 license as part of Berghahn Open Anthro, a subscribe-to-open model for APC-free open access made possible by the journal's subscribers.

\title{
ARTICLES
}

\section{THE LiMITS OF KNOWING OTHER MINDS} Intellectual Disability and the Challenge of Opacity

\author{
Patrick McKearney
}

\begin{abstract}
New care workers in Britain typically struggle to understand, on their initial encounters, people who communicate atypically due to their intellectual disabilities. But they are required to provide care that is attuned to these individuals' desires and intentions. Why, then, does a care organization called L'Arche UK make it harder for carers to learn what is going on inside these people's minds? I argue that doing so does not prevent the acquisition of essential knowledge, but rather trains new carers to relate to those with intellectual disabilities as opaque. This creates a more involved relationship that opens up the possibility of forms of status and intimacy otherwise closed to such peoplethereby raising questions about the supposedly fundamental role that transparency and knowledge play in knowing others.
\end{abstract}

Keywords: care, disability, ethics, Intellectual Disability, L’Arche, mind, opacity, Theory of Mind

Some loves are exclusive and demand a blindness in other quarters.

- Martha Nussbaum, Love's Knowledge

What role does knowledge about what is going on in other people's minds play in knowing and relating to them? When new carers arrive to work in the British care home for adults with intellectual disabilities ${ }^{1}$ in which I conducted fieldwork, they have trouble understanding and relating to those they are there to support. Newcomers tend to respond by trying to gain access to the minds of those with intellectual disabilities. They give up on trying to talk to these individuals directly, and instead ask more experienced carers for thirdperson information about these people's interior lives-suggesting that they 
presume the people in question are incapable of communicating something of themselves directly. Many care organizations go along with this approach by giving newcomers third-person information about what is going on inside these individuals' heads in order to facilitate the process of getting to know them. And this method fits well with the process of learning to care for these people, which in this context involves constantly discerning someone's needs, desires, and intentions. Carers thus learn to read the minds of individuals who at first seemed impossible to understand in order to take care of them.

I worked in an unusual organization called L'Arche that, in stark contrast, gives none of this information at first, and instead insists that carers continue to relate directly to those with intellectual disabilities. This approach puts carers in a difficult situation: it stops them from acquiring the kind of information they feel would remedy the situation, and it prevents them from evading interaction with the person altogether. In due course, L'Arche, like any other organization, also teaches these carers to discern the thoughts and feelings of these individuals. This enables carers to compensate for the ways in which a person may struggle to communicate their needs and desires, ensuring that they receive care attuned to them as individuals. But I argue that denying carers this kind of information about the other's mind at first is not simply a way of preventing the inevitable acquisition of essential knowledge. It also trains carers in a quite different form of relationality and raises questions about how essential this knowledge really is.

Carers in L'Arche learn to interact with these individuals even though they may seem opaque by not probing for objective knowledge about what is going on inside their minds, but rather waiting for them to communicate in unexpected ways. I contend that this cultivates a new kind of interactive space in which people with disabilities emerge as communicators in their own right. L'Arche's way of training carers to relate to these individuals even while remaining opaque is part of its broader attempt to transform the relationship of care into a site of potential friendship - and thus a site in which these individuals have their needs catered to but are also apprehended as agents with the capacity to affect others.

My analysis of this case draws upon and contributes to a recent anthropological debate about the epistemology and ethics of reading other people's minds. Interest in 'opacity' centers around particular small-scale societies that appear to deny, disable, or prohibit the possibility of having knowledge about what is going on in the minds of other people. ${ }^{2}$ The Urapmin of Papua New Guinea are at the heart of the debate because Joel Robbins (2008: 426) describes them as holding a severe "opacity doctrine" that forbids all talk of another's interior states as a serious violation of that person's dignity and privacy (see also Robbins and Rumsey 2008: 416). Robbins (n.d.: 3, 16, 23) never heard any of the Urapmin talk about what was going on inside someone's head, even in situations where it would have obviously been to their advantage to do so. ${ }^{3}$ The central question is whether to take this as evidence that the Urapmin really do 
refrain from thinking about what is going on inside each other's minds. Is such a thing even a cognitive possibility, let alone a likely social reality? Or is opacity simply a norm that the Urapmin must publicly respect even if internally they attempt to read other people's intentions all the time?

I turn from thinking about those with the same cognitive capacities in radically different societies to a different kind of limit case: those with different cognitive capacities within Western societies that have typically been imagined as the known and predictable counterpoint to the exciting and strange world of opacity claims (Keane 2008: 473; McKearney and Zoanni 2018; Robbins and Rumsey 2008). The case I describe does not contribute directly to the strictly cognitive question of the debate so far.Carers in L'Arche actively and conspicuously try to read the minds of people with disabilities-and this is related to the contextual acceptability of attempts to access other people's minds in British society more widely. But I demonstrate that even in this context the possibility of not trying to pre-empt or know what another is thinking is intelligible, widespread, and ethically significant. So I broaden out the psychological question into a wider investigation into how dynamics of opacity and transparency are related to how people relationally "approach the task of understanding one another” (Robbins and Rumsey 2008: 410; see also Astuti 2012).

Putting my data in relation to this debate leads me to make three arguments. First, that questions about the legibility of another person's mind are of widespread ethical and epistemological concern beyond the small-scale societies that have been at the center of the debate. Second, that relating to others as transparent is as culturally learned, debated, and particular as opacity. Third, that relating to others as opaque creates not only absence or ignorance but also different ways of knowing people as different kinds of people-an issue of central importance to facilitating different forms of interaction and relationship with those who might otherwise seem impossible to relate to. I contend, against the framing of the opacity debate thus far, that the way we gain knowledge about someone is not a single, neutral, cognitive, or epistemological process that might be affected by differing cultural norms. Rather, knowing another is always already an ethical and relational matter-and thus necessarily inter- and intra-culturally diverse.

\section{The Need for Knowledge}

I conducted 15 months of ethnographic research on organizations in the UK that receive government funding to care for people with intellectual disabilities. In particular, I trained to become a carer in one organization called L'Arche, which I still visit regularly. I focused on this organization's presence in a British city where it supports 30 adults with intellectual disabilities who have varying levels of need, living in houses and flats spread out across a residential area. I took up 
a full-time position to work as a carer in L'Arche, primarily in one house for five adults who lived there permanently.

The care in the house was organized by two managers and provided by a team of 15 carers, who circulated between different houses. About half of these carers had worked in L'Arche for five years or more. They were typically female, between 30 and 60 years old, from Britain or Continental Europe, and often more middle class and educated than a typical carer in the UK. But, as per many care providers in the UK, turnover is high in L'Arche, with about one-third of the caring workforce being replaced every year. Five other carers (younger, but otherwise demographically similar to the more experienced carers) joined the team at the same time as me. Based on extensive notes I took as we were trained to do our job, I focus here on how we were guided through the process of getting to know those with disabilities, and in particular on the role that knowledge about their minds played in it.

When I and other new carers arrived at the house for the first time, we all found it very difficult to communicate with and understand the long-term residents. Sarah uses a wheelchair and does not use words. ${ }^{4}$ When newcomers first meet her, she often grabs their arms and says "Wa!” loudly. Most people find this behavior disconcerting, and for some it is positively scary. Few know how to understand what Sarah is trying to communicate, and how to respond as a result. Emma told me in an interview that she found it "shocking" when she first arrived and worried, "Will I manage to understand these people? Will I feel comfortable to live here for one year?" When individuals such as Sarah deviate from interactional scripts, their partners in interaction find that the pathways they expected to go down have been blocked, and they do not know how to find new ones.

Newcomers encountering this difficulty frequently search for greater transparency by detaching from second-person interaction with the individual. One young boy visiting L'Arche was so shocked that Sarah could not speak that he went around the room pointing at other people and asking his mother, "What about that one? Can they talk?" I and other newcomers to L'Arche typically turned to a more experienced carer to ask quietly, "What does she mean?," "Does she speak?," or "Is she angry?" We lost faith that Sarah was an agent "whose reasons, mysterious as they might be, [we could] in principle come to understand” (Langton 1992: 487). Instead of carrying on talking to those with cognitive disabilities, when we were stumped as to how to go on, we resorted to third-person questions about these individuals, their mental capacities and intentions. ${ }^{5}$ When I became more experienced myself, newcomers would often ask me what condition Sarah had, whether her noises "meant" anything, or whether anything was going on in her mind at all. I saw other people do precisely the same in other organizations too and in more public settings. It is also a common response to those with dementia, autism, and mental illness (Antze 2010; Luhrmann 2007; Mattingly 2017; Taylor 2010). ${ }^{6}$ 
This sense of Sarah's (and others') opacity presents a problem for the ethical endeavor of caring for such individuals for two quite different reasons. The first is that new carers do not know how to continue interacting with Sarah in the second person, a mode of address central to respecting another adult as free and equal in Britain. In public interactions, the imperative of the second-person mode of address is connected to having control over what one discloses of oneself-encoding the role of the listener in public contexts as one of deferring to others' authority to speak their own mind (Stasch 2008; see also Keane 2008: 478; Laidlaw 2013: 158-161). One must, in other words, relate to others as if one does not know what they are going to think, feel, or desire in order to treat them as if they are free, and as if they have a private space inside them that is not transparent to you. The "typically English distaste for psychological explanation" (McEwan 2013: 68) and speaking for someone else is based on the threat it poses to people's privacy and independence. One must treat individuals as if they are, in certain ways opaque, in order to accord them the freedom of an equal. We will return to how to interpret this semblance of opacity in due course.

This mode of address is not central to respecting children. It is common for adults to speak about children in their care or about the contents of their minds as if children are knowable and transparent in some respect (Ochs and Schieffelin 1984; cf. Schieffelin 2008: 434). People with disabilities-and intellectual disabilities in particular-have often been imagined to be closer to children than to adults because of their reliance upon specialized care, and are thus often denied this form of respect (Johnson 1998; Thomson 1998). As Michael Williams’s famous poem “Connah’s Quay” puts it:

"Does he take sugar in his tea?"

Hello; why not ask me?

Reforms within public culture, civil society, and government policy have brought about a shift that has reshaped what is seen as acceptable on this front (Welshman and Walmsley 2006). Carers are supposed to accord people with intellectual disabilities the same respect as other adults. The kind of third-person questions that carers ask about these individuals does not accord them this sort of respect. So the difficulty that new carers have in knowing how to carry on interacting with these individuals directly, in the second person, means that they, quite unintentionally, end up effectively excluding these individuals from equal adult relationality-interacting around them, instead, in a mode more appropriate to children.

The second reason that opacity presents a problem is that carers' inability to read the minds of those with disabilities also puts in jeopardy the activity of providing care. Euro-American understandings of care tend to assume that supporting others goes beyond giving them what you think they ought to have (Aulino 2016; see also Kittay 1999; Mol 2008). It relies, instead, upon being in 
touch with other people's internal world-responding to their emotions, desires, and choices by alleviating distress, discomfort, and powerlessness. To achieve this, carers must know whether Sarah's “Wa!” means she is in terrible pain, or asking for a glass of water, or simply being playful. This may even be a matter of life or death in certain situations. In the context of people who can communicate in standardized ways, providing this kind of attuned care may involve simply following another person's orders. But in the case of someone like Sarah who cannot communicate, it necessitates a more transparent kind of gaze that sees beyond what a person is able to express to comprehend their deep-seated needs, intentions, and desires. And this is typical of care in this context more generally, which does not rely solely on the choices a person can explicitly render front of stage, but also gets involved backstage in 'tinkering' with an individual's interior life (Driessen 2018; McKearney 2020; Mol 2008; Pols et al. 2017). Without being able to see beyond Sarah's opacity, carers cannot provide this kind of care.

\section{Acquaintance without Transparency}

Getting to know, and understanding how to interact with, a particular person with disabilities is central to carrying out each of these tasks. But L'Arche approaches teaching carers to do that differently from other organizations, in a way that raises questions about just what it means to interact and get to know someone.

Through a long process of formal and informal training, new carers in L'Arche eventually learn the kind of detailed information that they crave in their initial encounters. In our first months in L'Arche, we read files that detailed the distinctive needs, preferences, and abilities of the people with disabilities. These contained advice on how to interpret the communication and behavior of the people we were there to support: such as when Martha says, "Pù," she can mean 'pub', 'café', or 'restaurant'; or when Sarah repeatedly bites her wrist, it is because she is distressed. More experienced carers would often reiterate, and elaborate on, this advice during informal interaction around the home.

We shared this tacit knowledge at team meetings where, away from close contact with those with disabilities, managers and carers discussed their mental capacities and inner lives more explicitly. As newer carers, we would recount forms of behavior and communication that we were confused by. More experienced carers would debate with one another how to interpret the person with disabilities, what they were communicating, and how we should respond as a result. In this way, in the intimacy of daily rhythms of life in the home, we learned both a great deal of information from those who had been interpreting these individuals for a long time as well as how to render them transparent and legible to ourselves. We learned to understand what had at first seemed incomprehensible outpourings as, instead, the expression of moods, desires, and 
choices of an intelligible internal world. We became able to provide care that was attentive and responsive to them.

Carers in organizations other than L'Arche learn the same kind of information. When I made my first visits to other organizations that provided care differently from L'Arche, experienced carers used this kind of information to remedy my inability, as a newcomer, to understand a person with disabilities. They would try to soften the blow by saying, quite publicly, "He has autism," or Down syndrome, or anxiety. When a man who used a wheelchair took hold of my arm suddenly, a care worker said, "Sorry. Watch out. He grabs people." In this way, experienced carers followed newcomers in abandoning the secondperson mode of address in order to transmit the information they had acquired behind the veil of opacity, through their transparent care, about what was going on inside these people's heads. They rendered my third-person questions quite normal, reassured me that I was not being rude by failing to maintain direct interaction, and domesticated the person with disabilities in my mind, making them seem less unpredictable and unknowable.

When I and other newcomers first arrived in L'Arche, in stark contrast, more experienced carers did not help us in this way. No one offered any reassuring explanations. They did not stop Sarah from grabbing my arm, nor did they explain what she was doing. Without domesticating the behavior of persons with disabilities in any way, they leave newcomers alone in their confusionmaking it seem like it is their fault for failing to understand or respond. Experienced carers may gently remove Sarah's arm and say to her, "Oh, you like new people don't you Sarah?” But they will never say what condition Sarah 'has'. Nor will they say anything as an aside to the newcomer. Indeed, when new carers ask third-person questions about those with disabilities as a quiet and private aside, they tend to be ignored.

If experienced carers do respond, they will answer by directly speaking to the person with disabilities. Even then, their answers often seem evasive and confusing, rather than instructive. Take, for instance, one dinner time during my research in L'Arche when an experienced carer named Marla was imitating Sarah's distinctive vocalizations by saying "Li" with her hand over her mouth before putting her finger inside her cheek to make a 'pop' sound. Sarah was laughing enthusiastically. I asked Marla, "Do her sounds mean anything?” Marla did not respond to me directly. "I think you just enjoy them, don't you, Sarah?" she said to Sarah. Looking for more information that might help me navigate this situation, I tried again: “Does she understand words?" I was met not with an answer, but with a story.

When I first arrived, I didn’t do personal care with you, Sarah, for a while. And when I first did it, I assumed that you didn't really know what was happening. I didn't know what I was doing, and at one point had to think for ages about what to do next. And you just sat there very patiently and 
quietly. When I worked out what the right thing to do was finally, you looked at me dead in the eye, and then laughed at me!

This story only left me more confused about whether Sarah was capable of verbal interaction. It portrayed her as, in contrast to my initial impressions, someone who was highly communicative. The contrast was jarring in itself, but so was the way in which it was told, as if it should be obvious to me that Sarah does indeed speak. And the same went for the matter-of-fact way in which carers told me that Sarah had cooked the meal we were eating, gone for a walk earlier, and spoken to her sister when it seemed to me that she would be quite incapable of doing any of these tasks (see also McKearney 2019). It gave the impression that it was not Sarah, but I who had the 'learning difficulties' (Young 2013: 141-142, 183-184; 1997; see also Williams 2014: 125).

Experienced carers in L'Arche do not mobilize the information they have to help newcomers relieve the difficulty of opacity in their initial encounters. They make it quite clear, in fact, that it is disrespectful for new carers to seek such information from them rather than from the people with disabilities themselves. This blocks off new carers' initial attempts to uncover information about those they are trying to get to know, rendering these individuals more mysterious than transparent. New carers do eventually learn much of this information through the training process, as I have already described. But they are made to wait for it. They are not given that knowledge upon arrival in order to relieve the difficulty of opacity in their initial encounters. At first, their initial bafflement deepens. Their escape route from this demanding encounter is barred, and they are forced to interact with the people with intellectual disabilities while lacking any reassuring insight into their heads.

When new carers are eventually taught this information, it is in contexts more restricted, more private than the spaces in which it is transmitted in other organizations. Long-term carers teach how to support someone with a particular set of tasks from the specifically designated frame of team meetings, or from private files kept locked in a cupboard. There are limits on transmitting this information in the third person. I cannot think of an occasion when I was told what condition someone 'had', and only rarely found such information buried deep within a person's file. Even less obviously objectifying information is rarely given without redirecting to the voice of the person with disabilities. A person's file, for instance, is written in the first person, as if the person with disabilities has written it him/herself. And when more experienced carers teach a newer one in the presence of someone with disabilities, they use only the second-person mode of address to those with disabilities. When I asked Peter why Sarah bites her wrist, he responded: "I think you do that when you're feeling angry, don't you, Sarah?"

Carers do not broadcast information about their knowledge of these individuals' minds (such as the extent of their disability, their needs in daily life, or the 
type of 'problem' they have) in areas such as the kitchen and sitting room in which people with intellectual disabilities interact with one another and with friends and guests who are not involved in their care. In these settings, old hands in L'Arche evade direct questions about a person's competence at a certain task; instead, they talk about people with disabilities doing things it is hard to believe they are capable of, and tell stories in which a person displays surprising abilities (McKearney 2018, 2019). This demarcates certain spaces in the home as focused on private care in contrast to those in which people interact socially.

These practices do not indulge the search for the kind of transparency or knowledge that carers will eventually learn. At first, they do more to reinforce the initial sense that new carers have of these individuals as opaque. They restrict the possibility of uncovering information about someone with disabilities in public settings other than through a direct encounter with them. They constrict the ways in which carers can use and transmit the knowledge they gain through care in their interactions with these individuals outside of that care. Quite unlike other organizations, more experienced carers in L'Arche slow down, thwart, and undermine new carers' active search for access to these people's mental interiors. New carers are required to start learning how to respect those with disabilities before they learn the information that they will eventually use to provide attentive care.

\section{Different Types of Knowing}

L'Arche's approach represents something of a puzzle. Robbins (2008, 2020, n.d.) argues that the opacity prohibitions among the Urapmin fit within a form of interactive life that is very different from Euro-American norms. The Urapmin do not promise, apologize, or hold one another to account for intending something. Their social life does not rely on practices in which it is necessary to broadcast one's intentions. The restrictions in L'Arche seem less fitting. They emerge in a Euro-American context that is often treated as the bastion of intention reading (Carey 2017; Keane 2002; Robbins 2001, 2008).

Promising, apologizing, and holding other people to account for their intentions are regular practices within Britain-as are direct ways of expressing one's inner state to others. It is common in this context, also, to see getting to know and communicating with another as a process of sharing one's thoughts and feelings with another (Carey 2017; Reddy 1979). I have already described, furthermore, a fit between the kind of access needed to have that kind of intimacy and the kind of transparency necessary to provide care, in which one must know another's inner needs and desires in order to provide support in tune with that individual's intentions, regardless of whether he or she is capable of expressing them. In this context, getting beyond any initial obstacles of opacity that are 
presented by those with disabilities is considered essential to keeping them alive and to interacting with them. That is why, in other care settings, experienced carers go with the grain of new carers' quest for transparency, information, and access by answering their third-person questions about those with disabilities. By contrast, in L'Arche, experienced carers use their authority in this situation to reinforce the normativity of the second-person mode of address and to make it more difficult for new carers to find out such information. Why?

L'Arche adheres to the second-person mode of address in order to try to respect those with disabilities as equal adults, even in the face of communicative difficulties. But this approach looks decidedly impractical. It seems to curtail carers' attempts to render these individuals transparent in order to care for them. And maintaining the ethical normativity of the second-person mode of address appears to do nothing to enable carers actually to carry it out. The whole difficulty of the initial encounter is that new carers do not know how to relate to these individuals in the second person when they first arrive. The difficulty is not that carers wish to depart from the second-person mode of address, but that, in the face of communicative difficulty, it becomes a hollow and wooden imperative rather than a live and full way to actually relate to another person.

These difficulties can be articulated through Webb Keane's alternative reading of the Urapmin material. Keane $(2008,2015,2018)$ argues that the Urapmin's culturally distinct mode of respect could never have the power to disable all forms of interaction that rely on intention reading, and thus all knowledge of one another's inner life, as Robbins claims. Mind reading, Keane argues, is essential to all social life-to coordinating our actions, communicating our thoughts, and simply interacting in the first place. The psychological mechanism is so basic that it would take far more than a particular social norm to disable it (see also Astuti 2012). Opacity practices do not indicate an epistemological problem about whether or not people can access one another's minds (Keane 2008: 474) but rather an ethical problem about what to do with the fact that they can (ibid.: 477). Prohibitions about talking about others' minds do not point to “deep, culturally specific, cognitive differences" (Keane 2015: 125), but to a situation in which people are required emphatically to deny "something they are in fact doing” (ibid.: 131; see also Laidlaw 2013: 159). Keane's argument offers a way to articulate the difficulty that new carers face when they cannot read the intentions of those they are supposed to support, and of the subsequent hollowness and impossibility of the second-person mode of address. Even if the secondperson mode of address appears to involve treating another person as opaque, in fact it would seem to rely on intention reading just as much as transparent care.

But Keane's argument does not help us ask whether there might be a logic to L'Arche's maintainance of the normative status of this mode of address, or whether doing so might affect interaction in interesting ways. This is because Keane's dismissal of the idea that opacity practices might affect how people 
really know one another's minds encourages us to think that there is a more basic and true way of knowing another's mind (a cognitive one) that sits underneath the particular (ethical) modes of respect that cultures might put on top. I argue, instead, that this opaque mode of respect does not simply cover up a more fundamental process of intention reading, nor does it prevent or delay carers from getting to know these individuals. Instead, transparency and opacity in this context are different "practices of listening" (Robbins 2008: 422) that constitute different ways of knowing these individuals as different kinds of people.

\section{Being Known Beyond Care}

People can be known as many things in different aspects of their lives. Adults in Britain often depend on relationships in which they are cared for. But they also often have relationships that are not totally defined by care in work, friendship, or romance. People with intellectual disabilities are rarely employed, have few romantic relationships (Kulick and Rydström 2015), and have almost no friends who do not also have intellectual disabilities (Gravell 2012). It is rare for them to be known in depth by people other than their families and the professionals who support them. Living in heavily state-regulated homes, transparent care dominates their lives so totally that they have few contexts in which to be known in another way. People with intellectual disabilities have few opportunities to be known by others as adults or to experience the forms of respect, autonomy, and recognition that come with giving care, living independently, or inhabiting relationships not defined by care at all. People with intellectual disabilities are known. They have little choice but for the most intimate, embarrassing, and quotidian details of their lives to be revealed to their carers and to the state (Johnson 1998). But this is a limited way of being known; not because it places limits on the amount of information that can be acquired, but because information is not all there is to being known.

Contemporary policy in the UK is a response to the idea that adults with intellectual disabilities should not be confined to being care recipients, but rather enabled to be seen and heard in mainstream society as equal adults, as friends, as consumers, as citizens, as lovers (Welshman and Walmsley 2006). And it is a response, also, to the idea that they should get to choose how they do so, with the same power to control what of themselves they keep private and what they decide to reveal in public. All care organizations in the UK are thus mandated to give their care in such a way that it does not become totalizing, but rather enables people with intellectual disabilities to be known in other contexts as other kinds of people.

Most organizations pursue this aim by trying to make these individuals independent in the local 'community'. They regulate the caring relationship 
closely, restricting the extent to which carers can disclose anything about their own personal lives, share meals and gifts, have physical contact with those they support, or spend time with them outside of working hours. This draws a strict distinction between relations of transparent care and other kinds of adult and intimate relations in which those with disabilities can be agents. But this division of labor still leaves the burden of disclosure on people with intellectual disabilities: it is they who need to appear to others in recognizable ways. And this may be part of the reason why they form so few relationships outside of care.

L'Arche takes a different approach. The organization started in France in the 1960 s as a communal approach to disability care, in which those with and without intellectual disabilities live together (Spink 2006). Its central message, often articulated in Christian terms by its Roman Catholic founder, Jean Vanier (1995), is that relationships in such communities can develop into reciprocal ones, involving not just care by a competent party for a designated 'vulnerable' other, but also mutual friendships between equally needy people. L'Arche in the UK, inspired by this tradition and vision of mutuality, uses government funding to go in a direction that is different from other care organizations. It does not carefully separate care from friendship but explores whether the two might co-exist in the same relationship. It ignores many of the boundaries that other organizations strictly enforce. Many carers receive a small stipend in compensation for providing 46 hours of care a week, while they live (as I did during my fieldwork) in the large, communal houses where they eat, pray, and socialize with those they support beyond the hours that they are contractually employed.

Carers join those with disabilities as well as long-term friends who do not work for L'Arche in creating a social life centered on the care home itself (McKearney 2017). In other organizations, the whole social space of care is defined as a private one in which intimate relationships will not be formed. Care is understood to be an unpromising site for people with intellectual disabilities to form relationships; instead, the local community is viewed as the space in which these individuals might be revealed, related to, and apprehended as something more than dependents. But L'Arche aims to transform the site of care also into a site of adult relationality-a quasi-public place in which people with intellectual disabilities might be related to, not only as care recipients, but also as potential friends.

LAArche's restrictions on more transparent forms of interaction upon arrival are directed toward this end. L'Arche places carers in a difficult interactional space, where they feel they do not have enough information to carry on. But L'Arche does not indulge that feeling by dispelling opacity with transparency. Experienced carers do not take transparency to be just one way of acquiring morally neutral, cognitive information about these individuals that is essential to knowing them tout court. They see it as a distinct, contingent, and limited mode of relation. Not because it puts limits on the amount they can know about these individuals, but because it confines them to being known only as recipients of 
care. So carers in L'Arche do not give information that might endow newcomers with any secure knowledge about what is going on. Instead, they wean them off the seeming necessity of their questions about the other person's mind to teach them instead how to relate even though their questions remain unanswered.

Although this evidently does not disable carers' cognitive ability to read these people's intentions, it also does not grant carers transparent access to them. Withholding information about those with disabilities offers no way for the new carer to access, control, or penetrate the contents of those individuals' minds in their initial encounters. Unable to unearth things from inside their heads and thus domesticate those with intellectual disabilities in their imaginations, carers must instead learn "a posture of agency that is porous and susceptible of influence" (Nussbaum 1990: 180) that allows others to be "mysterious" and waits attentively to see what they reveal (Nussbaum 2001: 169; see also McKearney 2018; Mittermaier 2012). L’Arche turns opacity from an indication of absence into a sign of an unknown presence, and an inviting one at that-turning inaccessibility from a cause to doubt the other persons' interiority into a faith in its veracity and vivacity (Jenkins 1999: 227). "Bewilderment and hesitation" are transformed from barriers to comprehension into "marks of fine attention" (Nussbaum 1990: 182) to a person as a person.

In denying the relief that a transparent way of knowing brings, L'Arche is not rigidly adhering to a wooden ideology of respect that ignores the universal practicalities of getting to know people, as Keane might argue. Rather, it is cultivating in carers a capacity to relate to opacity-and thus to put the interactional flesh back on the normative bones of the second-person mode of address without thirdperson information about these individuals (Robbins 2008: 428; see also Carey 2017; Keane 2018: 36). These interactive patterns, in stark contrast to transparent care or fleeting and fragile public encounters, give a person with disabilities the "ability to control what is hidden and what is to be revealed" in order to lay "claim" to "the distinctiveness of the first person position" (Keane 2008: 480; see also Stasch 2008). At the dinner table with carers trained to listen, people with intellectual disabilities play, speak, and affect others (McKearney 2018). They are not only the objects of information, but also the subjects of stories (Mattingly 1991; 1998: 285; 2014; see also Arendt 1958: 181-188; Langton 1992; MacIntyre [1981] 2007: 189, 206-212). They have a wide range of friendships in L'Arche, with people who support them at present, with those who have cared for them in the past, and with locals who visit the community on a regular basis.

\section{Conclusion}

This case complicates the assumption that transparency is a natural, universal, and simple way for humans to approach one another's minds, and that opacity 
is a quirk confined to a few societies that requires a distinct explanation. EuroAmericans are often imagined as practicing mind reading all the time, and as having no ethical problem whatsoever with doing so. But refraining from trying to pre-empt or know what another is thinking is intelligible, widespread, and central to respecting others in the UK as well. Questions about the legitimacy and possibility of accessing another person's mind have ethical significance much more broadly than in the few societies in which these issues are expressed through strict 'opacity doctrines'.

Robbins and Keane offer us different ideas about how the epistemology and the ethics of knowing other people's minds might be closely related. Robbins explores the possibility that an ethical norm might penetrate deeply into the way people cognize about each other to the point that it might disable our knowledge of others. Keane, by contrast, investigates the opposite direction of travel-how the knowledge that we inevitably already have of one another can become a matter of ethical reflection, concern, and regulation under particular moral regimes. But, from another perspective, both concur in keeping apart ethics and respect, on the one hand, and cognition and epistemology, on the other. They both treat the knowledge we have of one another as a cognitive matter that may or may not be affected by, or of concern to, an ethical norm. The result of this separation is that transparency is figured as a way of acquiring knowledge and relating intimately, while opacity is depicted primarily as about preventing knowledge and withholding from relating to others.

These contrasts do not make sense of L'Arche. Prohibiting carers from learning third-person information about the minds of those they support is about much more than just adhering to an ethical norm that either covers over or disables a cognitive process necessary to acquaintance. We know that carers are actively trained to learn certain kinds of information about the minds of those with disabilities. The prohibition is significant, instead, because it directs carers toward an encompassing form of ethical involvement with another that opens up new forms of relationality. These new forms make a real difference, not simply at the level of how people respect one another, but also at the level of how people know one another and what people know one another as. In this case, ethics and epistemology are not so easily separable.

This raises questions about the debate over the Melanesian material. Keane, for instance, draws attention to the co-presence of practices of transparency and opacity in Rupert Stasch's $(2008,2009)$ descriptions of the Korowai. Stasch argues that Korowai 'opacity doctrines' do not prevent all broadcasting of and speculating about intentions, but rather regulate what of one's knowledge it is appropriate to mobilize and express in different situations (see also Robbins and Rumsey 2008: 409). But Stasch's material and argument do not lead inevitably to Keane's conclusion that transparency is somehow the more fundamental of the two, because through it people acquire a certain kind of information 
that in opacity claims they simply deny. I take Stasch's point to be that the contrast between transparency and opacity practices is not best described as the presence or absence of information, the revelation or denial of what one really knows, and thus a matter of either cognition or respect. Rather, these practices constitute distinct ways of knowing another, each of which combines epistemology and ethics. Stasch's argument opens up the possibility that, even were Robbins to be wrong about the absence of intention reading among the Urapmin, he would still be right to argue that the ubiquity of opacity practices fundamentally shapes how people understand one another.

Opacity claims and dynamics are much more than denials or disablements of an unstoppable universal cognitive mechanism, and there is much more to understand about them than whether or not they do that. The seeming absence, restriction, and ignorance generated by opacity practices can also be a site for the emergence of alternative and unexpected forms of intersubjective interaction, new relationships between hearers and listeners, and thus new modes of reciprocity, intimacy, and recognition. This raises questions about just what kind of knowing opacity practices deny, about how central it is to knowing people, and thus what it is we really mean by knowing another. To finish, I expand on this thought by turning to philosopher Stanley Cavell's (1979b, 1987) reading of Shakespeare's Othello.

Cavell argues that Othello's difficulty is not that he lacks information about Desdemona. Othello's suspicions are not produced by her lack of transparency, nor can they ever be solved by it. Rather, he cannot relate to Desdemona as someone separate, other, and different from him because it entails losing control. His endless search for certain knowledge of what is going on inside her is not the necessary precondition of a relationship with her, but rather an ultimately murderous attempt to eliminate the "risks" and "vulnerabilities" of second-person interaction (Keane 2015: 99, 100). As Wittgenstein (1988: §§ 602-603) puts it:

Do I pay any mind to his inner processes if I trust him? If I don’t trust him I say, "I don't know what's going on inside him." But, if I trust him, I don't say that I know what's going on inside him.

Othello "knew everything" (Cavell 1979b: 43). He had enough information to trust Desdemona, "but he could not yield to what he knew, be commanded by it" (ibid.; see also Nussbaum 1990: 80; Williams 2016). He wanted to know her by penetrating her mind to access its inner depths and all the information inside it. But that would never enable him to acknowledge her, to live with her as a distinct first person in herself, unable to be controlled by him. Put differently, what Othello lacks is not certainty, but commitment. He is unable to 'live his skepticism' (Cavell 1979a). Cavell thus offers us the possibility of seeing the desire for transparency as a particular mode of relation-indeed, as a pathology that undermines certain forms of trust-and of seeing opacity as 
not the absence but itself a mode of relation (see also Backström 2013: 227; Reddy 1979).

Taking up Cavell's distinction between transparent 'knowing' as a matter of information and opaque 'acknowledging' as a question of recognition offers a new way to approach opacity (Cavell 1969: 254, 324; 1987). There is a parallel, in my case, between new carers and Othello: pursuing knowledge in the face of mistrust by trying to render another transparent. Other organizations occupy the role of Iago in this drama, indulging the quest for transparency. In L'Arche, however, the project is not to banish ignorance and opacity by whatever means, but rather to reshape the ethical habits through which carers approach the epistemological matter of knowing others' minds. L’Arche undermines new carers' search for information on the conviction that what they need "is not more knowledge but the willingness to forgo knowing" (Cavell 1969: 324). It encourages carers back into the difficulty of second-person interaction, in pursuit not of knowledge but of acknowledgment. It is not that there are limits to what they can know about people with intellectual disabilities through accessing their minds. It is that (this particular way of) knowing is, itself, limited. The opposite of transparent knowing is not the restriction of knowing or the absence of relation. It is a quite different form of connection-one that enables people with intellectual disabilities to be seen, heard, apprehended, and acknowledged in quite different ways.

Opacity practices are far more interesting than mere denials of a theory we already know to be true. They are not simply an ethical response to a culturally invariant epistemological process. They create new relational conditions in which individuals can interact with and know each other as different kinds of people. Whether and how we access one another's minds is not a cognitive question that can be separated from the ethical matter of how we stand in relation to people (Nussbaum 1990: 144). Ethical recognition is not something done with a piece of information about another after the fact. It is, in itself a relationship to another that constitutes a way of knowing them. 'Knowing' another person is never a purely cognitive matter. Perception is ethical, and relationships are modes of perception. To know is to relate. To know someone is not a universal, general, and neutral process of collecting ever more information about them; it is always done in a particular way through particular forms of relation. Or, put differently, collecting information about people is itself a particular way of knowing them-and one that may obscure other forms of relation that involve relinquishing the search for knowledge. 


\section{Acknowledgments}

I am grateful to Joel Robbins for initially encouraging me to analyze my ethnographic material in relation to the debate on mental opacity, and for many discussions ever since. I am also indebted to all of the participants in the "Theory of Mind" workshop that Joel and I organized in Cambridge in March 2018, for the ways in which the conversations surrounding that event developed my thinking on this topic in numerous ways. This piece has also benefited greatly from comments from two anonymous reviewers and discussions with James Laidlaw, Webb Keane, Danilyn Rutherford, and Rupert Stasch, as well as the ever-insightful reading of Giulia Contò.

Patrick McKearney is a Research Associate and Affiliated Lecturer at the Max Planck Cambridge Centre for Ethics, Economy and Social Change in the Department of Social Anthropology, University of Cambridge. His research focuses on the difference that regimes of care make to the material and subjective lives of people with cognitive disabilities. He has published on the themes of care, ethics, dependence, religion, and personhood, including special issues on mental diversity in Medical Anthropology and the Cambridge Journal of Anthropology. E-mail:pm419@cam.ac.uk

\section{Notes}

1. The validity of the category 'intellectual disability' is widely contested (Kittay and Carlson 2010; McKearney and Zoanni 2018). It is used in the UK to denote people assessed to have a significant cognitive impairment that started before the age of 18 and affects their everyday functioning. It is cognate with other terms such as 'learning disabilities' and 'cognitive disabilities'.

2. Such societies appear, for example, in Central America (Course 2013; Danziger 2006, 2010, 2013), North Africa (Carey 2017), Samoa (Duranti 1988, 2015), the Philippines (Rosaldo 1982), and Papua New Guinea (Robbins 2001, 2008; Rumsey 2008, 2013; Schieffelin 1990, 2008; Stasch 2008). Anthropologists working in these societies have reported that informants make at least one of three kinds of claim about others' minds: that one "can never know with any degree of certainty another person's thoughts, feelings, and intentions"; that one should not try to "guess or otherwise find out what people are thinking"; and that "one should not verbally state or imply what other people may be thinking" (Robbins 2020: 1; see also Robbins n.d.: 2).

3. Robbins (n.d.) relates that even when a relatively low-status woman did not appear for a momentous exchange with two of the busiest and most powerful 
men in a community, the men did not get angry, speculate on why she had stayed home, or try to hold her to account. "She would come when it was in her heart to do so, and we could never really know when this would be” (ibid.: 23).

4. Individuals' names have been changed to protect their privacy.

5. For an example of a loss of trust and the emergence of third-person doubts and questions about another's mind in Euro-America, see Garfinkel's (1964) famous ethnographic experiment and insightful analysis.

6. It is interesting that these interactional problems are often accompanied by a difficulty with seeing those with cognitive conditions as 'selves' at all-that is, as anything more than the 'shells' or 'husks' of people (Antze 2010; Banner 2014; Carlson 2009; Kittay 2010; Mattingly 2014; Taylor 2010).

\section{References}

Antze, Paul. 2010. "On the Pragmatics of Empathy in the Neurodiversity Movement.” In Ordinary Ethics: Anthropology, Language, and Action, ed. Michael Lambek, 310-327. New York: Fordham University Press.

Arendt, Hannah. 1958. The Human Condition. Chicago: University of Chicago Press. Astuti, Rita. 2012. "Some After Dinner Thoughts on Theory of Mind." Anthropology of This Century 3. http://aotcpress.com/articles/dinner-thoughts-theory-mind/.

Aulino, Felicity. 2016. "Rituals of Care for the Elderly in Northern Thailand: Merit, Morality, and the Everyday of Long-Term Care.” American Ethnologist 43 (1): 91-102.

Backström, Joel. 2013. “Wittgenstein, Follower of Freud.” In Ethics and the Philosophy of Culture: Wittgensteinian Approaches, ed. Ylva Gustafsson, Camilla Kronqvist, and Hannes Nykänen, 212-244. Newcastle upon Tyne: Cambridge Scholars Publishing.

Banner, Michael. 2014. The Ethics of Everyday Life: Moral Theology, Social Anthropology, and the Imagination of the Human. Oxford: Oxford University Press.

Carey, Matthew. 2017. Mistrust: An Ethnographic Theory. Chicago: HAU Books.

Carlson, Licia. 2009. The Faces of Intellectual Disability: Philosophical Reflections. Bloomington: Indiana University Press.

Cavell, Stanley. 1969. Must We Mean What We Say? A Book of Essays. Cambridge: Cambridge University Press.

Cavell, Stanley. 1979a. The Claim of Reason: Wittgenstein, Skepticism, Morality, and Tragedy. New York: Oxford University Press.

Cavell, Stanley. 1979b. "Epistemology and Tragedy: A Reading of Othello.” Daedalus 108 (3): 27-43.

Cavell, Stanley. 1987. Disowning Knowledge in Six Plays of Shakespeare. Cambridge: Cambridge University Press.

Course, Magnus. 2013. “Speaking the Devil’s Language: Ontological Challenges to Mapuche Intersubjectivity.” Language \& Communication 33 (3): 307-316.

Danziger, Eve. 2006. "The Thought That Counts: Interactional Consequences of Variation in Cultural Theories of Meaning." In Roots of Human Sociality: 
Culture, Cognition and Interaction, ed. N. J. Enfield and Stephen C. Levinson, 259-278. Oxford: Berg.

Danziger, Eve. 2010. “On Trying and Lying: Cultural Configurations of Grice’s Maxim of Quality.” Intercultural Pragmatics 7 (2): 199-219.

Danziger, Eve. 2013. "Conventional Wisdom: Imagination, Obedience and Intersubjectivity.” Language \& Communication 33 (3): 251-262.

Driessen, Annelieke. 2018. "Sociomaterial Will-Work: Aligning Daily Wanting in Dutch Dementia Care." In Care in Healthcare: Reflections on Theory and Practice, ed. Franziska Kause and Joachim Boldt, 111-133. Cham: Palgrave Macmillan.

Duranti, Alessandro. 1988. "Intentions, Language, and Social Action in a Samoan Context." Journal of Pragmatics 12 (1): 13-33.

Duranti, Alessandro. 2015. The Anthropology of Intentions: Language in a World of Others. Cambridge: Cambridge University Press.

Garfinkel, Harold. 1964. "Studies of the Routine Grounds of Everyday Activities." Social Problems 11 (3): 225-250.

Gravell, Carwen. 2012. Loneliness and Cruelty: People with Learning Disabilities and Their Experience of Harassment, Abuse and Related Crime in the Community. London: Lemos \& Crane.

Jenkins, Timothy. 1999. Religion in English Everyday Life: An Ethnographic Approach. New York: Berghahn Books.

Johnson, Kelley. 1998. Deinstitutionalising Women: An Ethnographic Study of Institutional Closure. Cambridge: Cambridge University Press.

Keane, Webb. 2002. “Sincerity, 'Modernity,' and the Protestants.” Cultural Anthropology 17 (1): 65-92.

Keane, Webb. 2008. “Others, Other Minds, and Others' Theories of Other Minds: An Afterword on the Psychology and Politics of Opacity Claims." Anthropological Quarterly 81 (2): 473-482.

Keane, Webb. 2015. Ethical Life: Its Natural and Social Histories. Princeton, NJ: Princeton University Press.

Keane, Webb. 2018. "Perspectives on Affordances, or the Anthropologically Real: The 2018 Daryll Forde Lecture.” HAU: Journal of Ethnographic Theory 8 (1-2): 27-38.

Kittay, Eva Feder. 1999. Love's Labor: Essays on Women, Equality and Dependency. New York: Routledge.

Kittay, Eva Feder. 2010. “The Personal Is Philosophical Is Political: A Philosopher and Mother of a Cognitively Disabled Person Sends Notes from the Battlefield.” In Kittay and Carlson 2010, 393-413.

Kittay, Eva Feder, and Licia Carlson, eds. 2010. Cognitive Disability and Its Challenge to Moral Philosophy. Chichester: Wiley-Blackwell.

Kulick, Don, and Jens Rydström. 2015. Loneliness and Its Opposite: Sex, Disability, and the Ethics of Engagement. Durham, NC: Duke University Press.

Laidlaw, James. 2013. The Subject of Virtue: An Anthropology of Ethics and Freedom. New York: Cambridge University Press.

Langton, Rae. 1992. “Duty and Desolation.” Philosophy 67 (262): 481-505. 
Luhrmann, T. M. 2007. "Social Defeat and the Culture of Chronicity: Or, Why Schizophrenia Does so Well over There and so Badly Here." Culture, Medicine and Psychiatry 31 (2): 135-172.

MacIntyre, Alasdair. (1981) 2007. After Virtue: A Study in Moral Theory. 3rd ed. Notre Dame, IN: University of Notre Dame Press.

Mattingly, Cheryl. 1991. "The Narrative Nature of Clinical Reasoning." American Journal of Occupational Therapy 45 (11): 998-1005.

Mattingly, Cheryl. 1998. "In Search of the Good: Narrative Reasoning in Clinical Practice.” Medical Anthropology Quarterly 12 (3): 273-297.

Mattingly, Cheryl. 2014. Moral Laboratories: Family Peril and the Struggle for a Good Life. Oakland: University of California Press.

Mattingly, Cheryl. 2017. "Autism and the Ethics of Care: A Phenomenological Investigation into the Contagion of Nothing." Ethos 45 (2): 250-270.

McEwan, Ian. 2013. Sweet Tooth. London: Vintage

McKearney, Patrick. 2017. "L'Arche, Learning Disability, and Domestic Citizenship: Dependent Political Belonging in a Contemporary British City.” City \& Society 29 (2): 260-280.

McKearney, Patrick. 2018. "Receiving the Gift of Cognitive Disability: Recognizing Agency in the Limits of the Rational Subject." Cambridge Journal of Anthropology 36 (1): 40-60.

McKearney, Patrick. 2019. "The Ability to Judge: Critique and Surprise in Theology, Anthropology, and L’Arche.” Ethnos. https://doi.org/10.1080/00141844.20 19.1640261.

McKearney, Patrick. 2020. "What Escapes Persuasion: Why Intellectual Disability Troubles 'Dependence' in Liberal Societies.” Medical Anthropology. https://doi. org/10.1080/01459740.2020.1805741.

McKearney, Patrick, and Tyler Zoanni. 2018. "Introduction: For an Anthropology of Cognitive Disability.” Cambridge Journal of Anthropology 36 (1): 1-22.

Mittermaier, Amira. 2012. "Dreams from Elsewhere: Muslim Subjectivities beyond the Trope of Self-Cultivation." Journal of the Royal Anthropological Institute 18 (2): 247-265.

Mol, Annemarie. 2008. The Logic of Care: Health and the Problem of Patient Choice. New York: Routledge.

Nussbaum, Martha C. 1990. Love's Knowledge: Essays on Philosophy and Literature. New York: Oxford University Press.

Nussbaum, Martha C. 2001. Upheavals of Thought: The Intelligence of Emotions. Cambridge: Cambridge University Press.

Ochs, Elinor, and Bambi B. Schieffelin. 1984. "Language Acquisition and Socialization: Three Developmental Stories and Their Implications.” In Culture Theory: Essays on Mind, Self, and Emotion, ed. Richard A Shweder and Robert A. LeVine, 276-320. Cambridge: Cambridge University Press.

Pols, Jeannette, Brigitte Althoff, and Els Bransen. 2017. “The Limits of Autonomy: Ideals in Care for People with Learning Disabilities.” Medical Anthropology 36 (8): 772-785. 
Reddy, Michael J. 1979. “The Conduit Metaphor: A Case of Frame Conflict in Our Language about Language.” In Metaphor and Thought, ed. Andrew Ortony, 164-201. Cambridge: Cambridge University Press.

Robbins, Joel. 2001. “God Is Nothing but Talk: Modernity, Language, and Prayer in a Papua New Guinea Society.” American Anthropologist 103 (4): 901-912.

Robbins, Joel. 2008. "On Not Knowing Other Minds: Confession, Intention, and Linguistic Exchange in a Papua New Guinea Community.” Anthropological Quarterly 81 (2): 421-429.

Robbins, Joel. 2020. “Mental Opacity.” In The International Encyclopedia of Linguistic Anthropology, ed. James Stanlaw. https://doi.org/10.1002/9781118786093. iela0257.

Robbins, Joel. n.d. "Opacity of Mind, Imagining Others, and the Coordination of Action: Melanesianist Reflections on the Ethics of Trust.” Unpublished manuscript.

Robbins, Joel, and Alan Rumsey. 2008. "Introduction: Cultural and Linguistic Anthropology and the Opacity of Other Minds.” Anthropological Quarterly 81 (2): 407-420.

Rosaldo, Michelle Z. 1982. "The Things We Do with Words: Ilongot Speech Acts and Speech Act Theory in Philosophy.” Language in Society 11 (2): 203-237.

Rumsey, Alan. 2008. "Confession, Anger and Cross-Cultural Articulation in Papua New Guinea.” Anthropological Quarterly 81 (2): 455-472.

Rumsey, Alan. 2013. "Intersubjectivity, Deception and the 'Opacity of Other Minds': Perspectives from Highland New Guinea and Beyond.” Language \& Communication 33 (3): 326-343.

Schieffelin, Bambi B. 1990. The Give and Take of Everyday Life: Language Socialization of Kaluli Children. Cambridge: Cambridge University Press.

Schieffelin, Bambi B. 2008. "Speaking Only Your Own Mind: Reflections on Talk, Gossip and Intentionality in Bosavi (PNG).” Anthropological Quarterly 81 (2): 431-441.

Spink, Kathryn. 2006. The Miracle, the Message, the Story: Jean Vanier and l'Arche. Toronto: Novalis.

Stasch, Rupert. 2008. "Knowing Minds Is a Matter of Authority: Political Dimensions of Opacity Statements in Korowai Moral Psychology." Anthropological Quarterly 81 (2): 443-453.

Stasch, Rupert. 2009. Society of Others: Kinship and Mourning in a West Papuan Place. Berkeley: University of California Press.

Taylor, Janelle. 2010. “On Recognition, Caring, and Dementia.” In Care in Practice: On Tinkering in Clinics, Homes and Farms, ed. Annemarie Mol, Ingunn Moser, and Jeannette Pols, 27-56. Bielefeld: Transcript Verlag.

Thomson, Mathew. 1998. The Problem of Mental Deficiency: Eugenics, Democracy, and Social Policy in Britain, c. 1870-1959. Oxford: Clarendon Press.

Vanier, Jean. 1995. An Ark for the Poor: The Story of L'Arche. Toronto: Novalis. Welshman, John, and Jan Walmsley, eds. 2006. Community Care in Perspective: Care, Control and Citizenship. Basingstoke: Palgrave Macmillan. 
Williams, Rowan. 2014. The Edge of Words: God and the Habits of Language. London: Bloomsbury.

Williams, Rowan. 2016. The Tragic Imagination: The Literary Agenda. Oxford: Oxford University Press.

Wittgenstein, Ludwig. 1988. Remarks on the Philosophy of Psychology. Vol. 2. Ed. G. E. M. Anscombe, Heikki Nyman, and G. H. von Wright. Chicago: University of Chicago Press.

Young, Frances, ed. 1997. Encounter with Mystery: Reflections on L'Arche and Living with Disability. London: Darton, Longman \& Todd.

Young, Frances. 2013. God's Presence: A Contemporary Recapitulation of Early Christianity. New York: Cambridge University Press. 